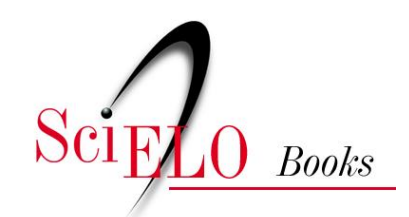

\title{
Seduepb
}

\section{Configurações do mal no romance Caim, de José Saramago}

\author{
Hudson Marques da Silva
}

\section{SciELO Books / SciELO Livros / SciELO Libros}

SILVA, HM. Configurações do mal no romance Caim, de José Saramago. In MAGALHÃES, ACM., et al., orgs. O demoníaco na literatura [online]. Campina Grande: EDUEPB, 2012. pp. 215-223. ISBN 978-85-7879-188-9. Available from SciELO Books <http://books.scielo.org>.

\section{(1)(9)(2)}

All the contents of this work, except where otherwise noted, is licensed under a Creative Commons Attribution-Non Commercial-ShareAlike 3.0 Unported.

Todo o conteúdo deste trabalho, exceto quando houver ressalva, é publicado sob a licença Creative Commons Atribuição Uso Não Comercial - Partilha nos Mesmos Termos 3.0 Não adaptada.

Todo el contenido de esta obra, excepto donde se indique lo contrario, está bajo licencia de la licencia Creative Commons Reconocimento-NoComercial-CompartirIgual 3.0 Unported. 


\section{Configurações do mal no romance Caim, de José Saramago}

Hudson Marques da Silva (UEPB/IFPE) ${ }^{1}$

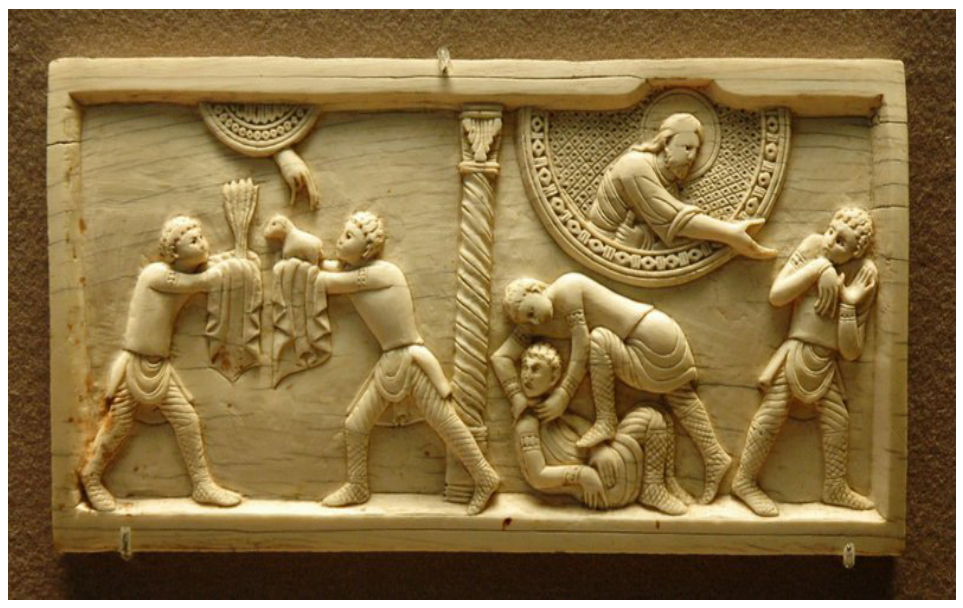

A obra literária Caim, o último romance de José Saramago, publicado em 2009, apresenta uma forte relação intertextual com alguns mitos do Antigo Testamento bíblico, o que a torna um palimpsesto. E isso se dá tendo em vista que "[...] o discurso não se constrói sobre o mesmo, mas se elabora tendo em vista o outro.”, como diz Eli Brandão (2008, p. 94). Desse modo, em uma perspectiva distinta e confrontante das interpretações eclesiásticas tradicionais, o romance saramaguiano remonta os seguintes mitos: Adão e Eva, Caim e Abel, Abraão e Isaac, a Torre de Babel, o encontro de Moisés com Deus no Monte Sinai, a destruição

1 Mestre em Literatura e Interculturalidade pela Universidade Estadual da Paraíba e Professor do Instituto Federal de Educação, Ciência e Tecnologia de Pernambuco - campus Belo Jardim. 
das cidades de Sodoma e Gomorra e, por fim, o contexto do dilúvio e a Arca de Noé, destacando, a partir da personagem caim, questionamentos sobre as ações de deus.

O romance Caim, assim como O Evangelho Segundo Jesus Cristo, de 1991, não foi bem aceito pela comunidade cristã, principalmente, pelos católicos portugueses, devido a seu caráter irônico, crítico e questionador em relação aos textos bíblicos originais, sobretudo no que se refere às ações de Deus. Em entrevista, Saramago (2009b) chegou a declarar:

A Bíblia é um manual de maus costumes, um catálogo de crueldade e do pior da natureza humana [...] Sem a Bíblia, um livro que teve muita influência em nossa cultura e até em nossa maneira de ser, os seres humanos seriam provavelmente melhores.

Contudo, vale salientar que este artigo comenta o texto de José Saramago e não os textos bíblicos. Portanto, como declara Antonio Carlos Magalhães (2008a, p. 15), Deus é um “[...] personagem literário, que, como qualquer outro personagem, cresce ou diminui à medida que dialoga com outros personagens."

Com base nessas premissas, o presente estudo propõe um diálogo acerca desses questionamentos perante as ações do Deus personagem, que neste romance surge como um ser antropomórfico, isto é, um Deus com atitudes e características humanas, portanto, passível a cometer erros, injustiças e até crueldades.

Enquanto re-escritura literária, o romance apresenta uma modificação na ordem cronológica dos mitos em relação aos textos bíblicos originais, além de uma estilística própria do autor, cujos sinais de pontuação não seguem o modelo proposto pela norma padrão: locais em que se grafariam ponto final (em fim de sentenças) e travessões (introduzindo falas de personagens), Saramago opta pelas vírgulas, promovendo uma confluência em que a voz do narrador e a voz das personagens se confundem. Além disso, identifica-se que os nomes de personagens e lugares cujas primeiras letras, normativamente, são grafadas em maiúsculas por representarem substantivos próprios, no romance aparecem em minúsculas. Por um lado, poder-se-ia presumir que isso se dá porque esses nomes, etimologicamente, possuem um significado, ou seja, não 
são nomes próprios. Por exemplo, a palavra adão, em hebraico $\mathbf{T}_{z}$ significa "terra vermelha" ou "homem vindo do barro"; eva (I-l) significa "vivente"; caim (ְְּ) significa "lança"; e assim por diante. Por outro lado, os nomes com primeira letra minúscula também podem representar um modo proposital de diminuir ou dessacralizar essas personagens. Por essa razão, os nomes das personagens, incluindo deus, serão grafados com primeira letra minúscula neste trabalho.

\section{Deus e o Demônio: duas faces de um mesmo ser}

O primeiro capítulo do romance narra o contexto do jardim do éden, onde se encontram adão e eva, que, inicialmente, não possuem a língua nem um idioma, mantendo-se, assim, em silêncio. Deus se irrita ao notar seu erro e, como diz o narrador, enfia-lhes "[...] a língua pela garganta abaixo." (SARAMAGO, 2009a, p. 9). Esse é o primeiro sinal de um deus potencialmente colérico, que falha, se arrepende e se enfurece.

Em seguida, surge um tema que tem levantado diversas interpretações ao longo do tempo, que é o pecado original. O texto de Saramago descreve a árvore como símbolo do conhecimento (do bem e do mal). Antes de comer do fruto, adão e eva não tinham acesso a esse conhecimento. Nesse sentido, questiona-se como poderia o casal não almejar o novo, o diferente, já que eles, representantes da humanidade, são seres de desejo, como ressalta Magalhães (2008b, p. 109): “A proibição sobre o fruto é porque o ser humano é um ser de desejos". E o fruto (que representa o conhecimento) é o objeto desejado. Se não fosse assim, não haveria razões para a proibição, uma vez que, como corrobora Rubem Alves (2005, p. 89, itálico do autor), "Não é necessário proibir que as pessoas comam pedras, porque ninguém o deseja. Só se proíbe o desejado."

No romance Caim, o narrador também propõe essa reflexão, uma vez que, sendo seres de desejo, deus não poderia esperar que adão e eva lhe obedecessem. Nessa mesma perspectiva, Magalhães (2008b, p. 109) declara que "O desejo do conhecimento é um desejo fundamental do ser humano, está em seus códigos mais profundos, não pode ser negado por nenhuma repressão." Nesse caso, deus surge como este repressor que proporciona um "mal" para o casal, primeiro por reprimi-los e, depois, expulsando-os do paraíso. 
Nessa ótica, os questionamentos sobre as ações de deus persistem no romance. Se o real objetivo divino fosse que adão e eva não comessem do fruto, diz o narrador, "[...] bastaria não ter plantado a árvore, ou ir pô-la noutro sítio, ou rodeá-la por uma cerca de arame farpado." (SARAMAGO, 2009a, p. 13). Em outras palavras, deus poderia ter evitado o tal pecado, se de fato fosse de sua vontade. Para realizar tais questionamentos, o autor se utiliza da ironia, ao introduzir elementos como a "cerca de arame farpado" no contexto do mito da criação.

Com a fertilidade de eva e subsequente nascimento dos irmãos, surge o protagonista da obra: caim. Em princípio, a relação entre os irmãos caim e abel era de compaixão e amizade recíprocas, como descreve o narrador: "Desde a mais tenra infância caim e abel haviam sido os melhores amigos, a um ponto tal que nem irmãos pareciam, aonde ia um, o outro ia também, e tudo faziam de comum acordo." (SARAMAGO, 2009a, p. 32).

Repentinamente, e sem motivo aparente, deus passa a acolher as oferendas de abel, a queima de cordeiros, e rejeitar as de seu irmão caim, a queima de vegetais. Desse modo, "Estava claro, o senhor desdenhava caim.” (SARAMAGO, 2009a, p. 33). O irmão abel, em vez de apoiar e confortar o irmão, pelo contrário, zombava dele:

Foi então que o verdadeiro carácter de abel veio ao de cima. Em lugar de se compadecer do desgosto do irmão e consolá-lo, escarneceu dele, e, como se isso ainda fosse pouco, desatou a enaltecer a sua própria pessoa [...] (SARAMAGO, 2009a, p. 33).

Por isso, com razão, o ódio é despertado em caim. Indaga-se por qual motivo deus havia realizado essa desfeita com ele, incitando o ódio que leva caim a assassinar seu irmão, como corrobora Salma Ferraz (2012).

Deus, ao questionar o crime cometido por caim, afirmando ter sido resultado de mais um de seus testes, tem como resposta: "[...] mas o primeiro culpado és tu, eu daria a vida pela vida dele se tu não tivesses destruído a minha [...]" (SARAMAGO, 2009a, p. 34). Deus explica sua façanha, "Quis pôr-te à prova", à qual caim responde: 
E tu quem és para pores à prova o que tu mesmo criaste, Como tu foste livre para deixar que eu matasse a abel quando estava na tua mão evitá-lo. [...] permitiste que abel morresse, Tu é que o mataste, $[. .$.$] matei abel porque não podia matar-te$ a ti, pela intenção estás morto, [...] (SARAMAGO, 2009a, p. 34)

Nessa cena, o próprio deus assume sua parcela de culpa pela morte de abel e, como acordo, põe a marca que protegerá caim de qualquer infortúnio. A marca, para deus, representa, como ele mesmo afirma, "[...] um acordo de responsabilidade partilhada pela morte de abel [...]" (SARAMAGO, 2009a, p. 35).

O romance aborda ainda o mito de abraão, fundador de três grandes vertentes religiosas da história: judaísmo, islamismo e cristianismo. Nesta cena, o narrador saramaguiano refere-se tanto a deus quanto a abraão como "filho da puta". O primeiro por ter ordenado o assassinato do garoto isaac e o segundo por ter-lhe obedecido:

O lógico, o natural, o simplesmente humano seria que abraão tivesse mandado o senhor à merda, mas não foi assim [...] Fiquem aqui com o burro que eu vou até lá adiante com o menino, para adorarmos o senhor e depois voltamos para junto de vocês. Quer dizer, além de tão filho da puta como o senhor, abraão era um refinado mentiroso, pronto a enganar qualquer um com a sua língua bífida, que, neste caso, segundo o dicionário privado do narrador desta história, significa traiçoeira, pérfida, aleivosa, desleal e outras lindezas semelhantes. (SARAMAGO, 2009a, p. 79)

Nota-se, portanto, que a personagem deus se apresenta como um ser cruel, uma vez que ordena ou permite crimes, bem como testa as outras personagens, além de egoísta, por exigir soberania, obediência de todos, desejando tudo apenas para si. O garoto isaac, por sua vez, questiona a ordem de deus, acusando-o de rancoroso por sempre condenar à ruína aqueles que não lhe correspondem: 
Pai, que mal te fiz eu para teres querido matar-me, a mim que sou o teu único filho, Mal não me fizeste, Isaac, Então por que quiseste cortar-me a garganta como se eu fosse um borrego, perguntou o moço, [...] a ideia foi do senhor, que queria tirar a prova, A prova de quê, Da minha fé, da minha obediência, E que senhor é esse que ordena a um pai que mate o seu próprio filho, [...] E se esse senhor tivesse um filho, também o mandaria matar, perguntou isaac, O futuro o dirá, Então o senhor é capaz de tudo, do bom, do mau e do pior, Assim é, Se tu tivesses desobedecido à ordem, que sucederia, perguntou isaac, $\mathrm{O}$ costume do senhor é mandar a ruína, ou uma doença, a quem lhe falhou, Então o senhor é rancoroso [...] (SARAMAGO, 2009a, p. 82)

Ao indagar se deus mataria seu próprio filho, o texto faz alusão a Jesus, que seria enviado à morte. Em outras palavras, deus está sempre ligado ao sacrificio. Agradar-lhe significa sacrificar-se ou sacrificar algo ou alguém, senão, haverá a punição.

No monte sinai, quando moisés encontra-se com deus e, enquanto isso, a multidão adora um bezerro de ouro, caim verifica a maldade de deus:

Não bastavam sodoma e gomorra arrasadas pelo fogo, aqui, no sopé do monte sinai, ficara patente a prova irrefutável da profunda maldade do senhor, três mil homens mortos só porque ele tinha ficado irritado com a invenção de um suposto rival em figura de bezerro, Eu não fiz mais que matar um irmão e o senhor castigou-me, quero ver agora quem vai castigar o senhor por estas mortes, pensou caim, e logo continuou, Lúcifer sabia bem o que fazia quando se rebelou contra deus [...] (SARAMAGO, 2009a, p. 101, negrito nosso)

Nesse trecho, nota-se que Caim dá razão a Lúcifer por ter ficado contra deus, pois sua crueldade supera a do Demônio. Deus julga todos, mas ninguém pode julgá-lo, pois ele decide todas as coisas e pode cometer qualquer injustiça. 
Nas cidades de sodoma e gomorra, milhares de pessoas, incluindo crianças, são mortas pelo fogo de deus, que as julga estarem cometendo pecados exorbitantes, inclusive práticas homossexuais (deus também é homofóbico). Os dez filhos da personagem job são mortos e sobre esse fato realizou-se uma espécie de assembleia no céu, quando ocorre o seguinte:

[...] realizou-se no céu uma nova assembleia dos seres celeste e satã estava outra vez entre eles [...] A mulher de job, de quem até agora não tínhamos ouvido uma palavra, nem sequer para chorar a morte dos seus dez filhos, achou que já era hora de desabafar e perguntou ao marido, Ainda continuas firme na tua rectidão, eu, se fosse a ti, se estivesse no teu lugar, amaldiçoaria a deus ainda que daí me viesse a morte, ao que job respondeu, Estás a falar como uma ignorante, se recebemos o bem da mão de deus, por que não receberíamos também o mal, esta foi a pergunta, mas a mulher respondeu irada, Para o mal estava aí satã [...] Sempre ouvi dizer aos antigos que as manhas do diabo não prevalecem contra a vontade de deus, mas agora duvido de que as coisas sejam assim tão simples, o mais certo é que satã não seja mais que um instrumento do senhor, o encarregado de levar a cabo os trabalhos sujos que deus não pode assinar com seu nome. (SARAMAGO, 2009a, p. 140)

Nesse trecho, a mulher de job classifica deus como covarde, na medida em que, por não ter coragem de assumir suas ações, responsabiliza satã por elas. Desse modo, a injustiça divina revela-se em várias cenas como: adão e eva foram expulsos do paraíso só porque desobedeceram a deus ao comerem do fruto, caim foi punido porque matou o irmão abel (fato incitado pelo próprio deus), abraão seria punido se não obedecesse a deus em assassinar seu filho isaac, os habitantes de sodoma e gomorra foram queimados por cometerem pecados (segundo deus) inadmissíveis, vários indivíduos foram mortos no monte sinai simplesmente por adorarem um bezerro de ouro. 
Embora multifacetado, o romance parece ter como principal foco questionar as ações de deus, que de forma impiedosa e cruel devasta milhares de indivíduos simplesmente por não atenderem às suas expectativas, sendo, portanto, um deus "mal".

No desfecho do romance, deus dirige-se a caim e declara: "Caim és, e malvado, infame matador do teu próprio irmão [...]" (SARAMAGO, 2009a, p. 172). A que caim replica: "Não tão malvado e infame como tu, lembra-te das crianças de Sodoma.” (SARAMAGO, 2009a, p. 172). Esse trecho, de certo modo, resume a principal tese apresentada aqui, que é a manifestação do lado mal de deus, ou deus e o Demônio como duas faces de um mesmo ser.

A personagem deus é o princípio e o fim, alfa e ômega. Com isso, o criador é responsável pela sua criação, incluindo o "mal" e o demoníaco. Essa concepção surge do princípio monoteísta que a tradição judaicocristã tem professado. É importante destacar que o deus e o Demônio sobre os quais se fala aqui, bem como todas as outras personagens, estão em nível literário, ou seja, trata-se de ficção, porém, uma ficção que tanto levanta novas perspectivas em relação aos textos bíblicos originais quanto aponta questionamentos sobre as interpretações que têm sido preservadas por eclesiásticos ao longo da história. Portanto, o romance Caim, de José Saramago, levanta debates acerca de mitos e tradições cuja legitimidade nunca é questionada, por ser tida como sagrada. 


\section{Bibliografia}

ALVES, Rubem. O que é religião? 6. ed. São Paulo: Loyola, 2005.

BRANDÃO, Eli. Resignação de Jó em "Ritual de Danação”, de Gilvan Lemos. In: FERRAZ, Salma et al. Deuses em poéticas: estudos de literatura e teologia. Belém: UEPA, UEPB, 2008.

FERRAZ, Salma. As Faces de Deus na Obra de um Ateu. 2. ed. Blumenau: EDIFURB, 2012.

MAGALHÃES, Antonio Carlos de Melo. A Bíblia como obra literária: hermenêutica literária dos textos bíblicos em diálogo com a teologia. In: FERRAZ, Salma et al. Deuses em poéticas: estudos de literatura e teologia. Belém: UEPA, UEPB, 2008a.

.; PORTELA, Rodrigo. Expressões do sagrado: reflexões sobre o fenômeno religioso. São Paulo: Santuário, 2008 b.

SARAMAGO, José. Caim. São Paulo: Companhia das Letras, 2009a.

Igreja católica critica novo livro de José Saramago. 2009b.

Disponível em: <http://www.josuegoncalves.com.br/familiaeGraca/artigos_ detalhe.asp? $\operatorname{cod}=1226 \&$ sessao $=10>$ Acesso em: 29 de ago 2010 .

\section{Imagem}

Disponível em http://4.bp.blogspot.com/_EmX17974UbE/

TRd3ZWTUBCI/AAAAAAAAEsY/KiEpXOzUfOE/s1600/caim-abel.jpg. Consultado em 07/10/2012 
